\title{
AVERSÃO À PERDA NAS DECISÕES DE RISCO
}

\section{AVERSION TO LOSS IN RISKY DECISIONS}

\section{AVERSIÓN A LA PÉRDIDA EN LAS DECISIONES DE RIESGO}

\author{
DANIEL ROSA DE ARAUJO \\ Universidade de Brasilia \\ daniel_adm_si@yahoo.com.br \\ CÉSAR AUGUSTO TIBÚRCIO SILVA \\ Universidade de Brasília \\ cesartiburcio@pq.cnpq.br
}

\section{RESUMO}

Os estudos de Finanças Comportamentais surgiram numa tentativa de enquadrar os estudos econômicos e financeiros dentro do comportamento humano, levando em consideração a natureza humana e aceitando o fato de que os agentes econômicos estão suscetíveis a erros e a ações irracionais. A base de Finanças Comportamentais está na Teoria da Perspectiva, que, segundo Bernstein (1997), expõe padrões de comportamento nunca reconhecidos antes pelos estudiosos e teóricos de processo decisório. A Teoria da Perspectiva aponta duas deficiências humanas que causam esses padrões. A primeira é o fato de a emoção muitas vezes destruir o autocontrole que é essencial à tomada racional de decisões. A segunda deficiência é o fato de as pessoas na maioria das vezes não entenderem de forma clara com que estão lidando, criando em suas mentes molduras cognitivas. Estes estudos mostraram que a irracionalidade em decisões e escolhas ocorre também entre investidores, executivos e administradores. Com base no estudo de Kahneman e Tversky (1997), este trabalho buscou verificar entre 180 estudantes de administração da Universidade de Brasília, como se dá a evolução do processo decisório destes alunos ao longo do curso, buscando verificar, desta forma, se os estudos de administração interferem nas tomadas de decisões quando estes se deparam com situações de risco. Os resultados encontrados nesta população específica mostraram que os estudantes pesquisados demonstraram pouca inferência de molduras cognitivas, levando a concluir que estes frames não ocorrem de forma generalizada, como afirmado por Kahneman e Tversky (Kahneman e Tversky 1984. apud BERNSTEIN, Peter L. Desafio aos deuses, p. 275). 


\section{repec}

Palavras-Chave: Finanças Comportamentais, Processo Decisório, Risco.

\section{ABSTRACT}

The studies of behaviorism finances had appeared in an attempt to inside fit the economic and financial studies of the human behavior, taking in consideration the nature human being and accepting the fact that the economic agents are susceptible the mistakes and the irrationals actions. The base of behaviorism finances is in the Theory of the Perspective that according to Bernstein (1997), displays studious never recognized standards of behavior before for and the theoretical ones to decision process. The theory of the perspective indicates two human beings of the deficiencies that cause these standards. First it is that the emotions often, destroy the self-control that is essential to take rational decisions. The second deficiency is that the people, in most of the time, do not understand clearly which they are taking care, creating a cognitive frame in its minds. These studies had demonstrated that irrationality in decisions and options also happens between the investors, the executives and the managers. Based in the study of Kahneman and Tversky (1997), this paper looked for to verify, between a 180 students of business of the university of Brasilia, how are doing the evolution of the decision process of these students through course, looking for to verify of such way, if the studies of the business take part with taking from decisions when these if they are exposed a risk situations. The results found in this specific population had demonstrated that the looked for students had demonstrated little inference of the cognitive frames, drive to conclude that these "frames" do not happen of a general way according to the affirmation for the Kahneman and Tversky (Kahneman and Tversky 1984. BERNSTEIN of apud, Peter L. Desafios aos deuses. p. 275).

Keywords: Behaviorism Finances, Decision Process, Risk.

\section{RESUMEN}

Los estudios de Finanzas Comportamentales surgieron en una tentativa de encuadrar los estudios económicos y financieros dentro del comportamiento humano, llevando en consideración la naturaleza humana y aceptando el hecho de que los agentes económicos son susceptibles a errores y a acciones irracionales. La base de Finanzas Comportamentales está en la Teoría de la Perspectiva, que, según Bernstein (1997), expone tipos de comportamiento nunca reconocidos antes por los estudiosos y teóricos de proceso decisorio. La Teoría de la Perspectiva señala dos deficiencias humanas que causan esos tipos de comportamiento. La primera es el hecho de la emoción muchas veces destruir el autocontrol que es esencial a la toma racional de decisiones. La segunda deficiencia es 
el hecho de las personas la mayoría de las veces no entienden de forma clara con que están tratando, creando en sus mentes marcos cognoscitivos. Estos estudios mostraron que la irracionalidad en decisiones y elecciones ocurre también entre inversionistas, ejecutivos y administradores. Con base en el estudio de Kahneman y Tversky (1997), este trabajo buscó verificar entre 180 estudiantes de administración de la Universidad de Brasilia, como ocurre la evolución del proceso decisorio de estos alumnos a lo largo del curso, buscando verificar, de esta forma, si los estudios de administración interfieren en las tomas de decisiones cuando éstos se encuentran con situaciones de riesgo. Los resultados encontrados en esta población específica mostraron que los estudiantes investigados demostraron poca inferencia de marcos cognoscitivos, llevando a concluir que estos frames no ocurren de forma generalizada, como afirmado por Kahneman y Tversky (Kahneman y Tversky 1984. apud BERNSTEIN, Peter L. Desafío a los dioses, p. 275).

Palabras-Clave: Finanzas Comportamentales, Proceso Decisorio, Riesgo.

\section{INTRODUÇÃO}

Executivos, investidores e administradores estudam em torno de dezesseis anos de suas vidas para que possam desempenhar suas profissões de forma legítima e eficiente. Aprendem sobre verdades e mentiras, modelos, pesquisas, estudos, análises, contextos, enfim, tudo padronizado e racional. Dentro de todo este contexto, imaginam-se como seres racionais, que estarão sempre agindo dentro da cientificidade que aprendem na academia. Acreditam que fazem tudo da melhor forma possível, levando sempre em consideração todas as variáveis, sendo melhores em inteligência, destreza, raciocínio etc.

A racionalidade do tomador de decisão foi abordada de forma clara na teoria da utilidade, que diz que em condições de incerteza as pessoas racionais processam as informações objetivamente; consideram toda informação disponível e respondem a novas informações com base em um conjunto claramente definido de preferências. Assim, investidores racionais ao comprarem uma ação ou ativos processam as informações disponíveis objetivamente, e os erros que cometem na decisão do futuro são aleatórios e não resultantes de uma tendência de otimismo ou pessimismo (BERNSTEIN, 1997).

A teoria dos jogos consolidou a idéia de comportamento econômico racional e da racionalidade na tomada de decisões econômicas. Nesse contexto, os mercados não poderiam ser previstos nem se comportar irracionalmente.

A irrelevância do pagamento de dividendos para o preço das ações foi defendida por Modigliani e Miller (1961), que defenderam a idéia de o pagamento de dividendos ser irrelevante para a riqueza total dos acionistas. Ou seja, em um mercado racional, o montante pago em dividendos não interfere na decisão de compra e venda de ações. Mais tarde, 
Sharpe (1964) formulou um modelo para avaliar ativos em condições de risco: o CAPM (Capital Asset Princing Model). Este modelo foi baseado na premissa de que o investidor é racional, avesso ao risco e sempre procura maximizar seu bem-estar.

Segundo Simon (1957), o papel do administrador é tomar decisões. Esse autor retrata como os administradores devem proceder em suas tomadas de decisão, estruturando-as e sistematizando o processo, agindo de forma extremamente racional, criando embasamentos segundo informações e análises das opções.

Porém, a racionalidade do processo decisório é difícil de ser suportada pelas nossas experiências diárias. Em diferentes situações em que se faz necessária a tomada de decisão, um indivíduo não consegue analisar todas as variáveis. Além disso, nem sempre as decisões são essencialmente racionais. Conforme afirma Shleifer (2000), as pessoas violam sistematicamente a regra de Bayes e outras máximas da teoria da decisão. Até porque a maioria das decisões importantes que precisam ser tomadas está em situações de pressão, incerteza, com alta complexidade, não estruturadas, e dificilmente tendem a se repetir da mesma forma. Evidencias psicológicas mostram que os indivíduos não se desviam da racionalidade de forma aleatória (SHLEIFER, 2000).

Em contrapartida ao modelo de racionalidade do processo decisório, duas teorias têm-se destacado na área financeira. A primeira, denominada de neuroeconomics, que não será objeto de discussão nesse texto por ser mais recente em termos do seu impacto acadêmico, trata da relação entre a medicina e as decisões econômicas dos indivíduos. A segunda diz respeito às finanças comportamentais ${ }^{1}$.

Kahneman e Tversky (1997) publicaram um dos trabalhos mais importantes que tratavam o comportamento humano em decisões econômicas. Este trabalho buscou por meio de experimentos, explicar dois vieses nos investidores: a aversão à perda e a contabilidade mental. O primeiro diz que temos mais medo de perder do que prazer em ganhar. O segundo diz que dividimos nossa riqueza em compartimentos mentais, sem analisarmos nosso patrimônio de forma agregada.

No Brasil, este assunto vem sendo abordado com crescente importância. No trabaIho desenvolvido por Viana (2005), foi abordado o efeito miopia e a aversão à perda nas decisões de risco. Viana verificou que o nível de aversão ao risco foi alterado ao se controlar a freqüência com que as pessoas avaliam suas perdas, mesmo com as probabilidades de ganhos e prejuízos sendo idênticas. Ou seja, a aversão ao risco neste trabalho foi alterada conforme os indivíduos recebiam informações sobre seus ganhos e perdas, deixando de lado a decisão racional baseada nas probabilidades. portamentais. 
Estes vieses ou anomalias no processo decisório humano confrontam teorias econômicas que têm como pressuposto a racionalidade dos investidores, tentando explicar de forma mais verídica as anomalias e bolhas existentes na realidade dos mercados. Analisando crises financeiras e os "efeitos bolhas" no mercado de ações, pode-se constatar que o modelo moderno de finanças não é capaz de explicar essas anomalias irracionais. Os estudos de Finanças Comportamentais surgiram numa tentativa de enquadrar os estudos econômicos e financeiros dentro do comportamento humano, levando em consideração a natureza humana e aceitando o fato de que os agentes econômicos estão suscetíveis a erros e a ações irracionais.

Um dos primeiros trabalhos e o mais influente na área de Finanças Comportamentais foi desenvolvido pelos psicólogos israelenses Daniel Kahneman e Amos Tversky. Na década de 1960, Kahneman desenvolveu uma pesquisa com os instrutores de vôo do exército israelense, chegando à conclusão de que o desempenho dos pilotos tende a regredir sempre ao desempenho médio. Se um piloto obteve um ótimo desempenho em suas três últimas aterrissagens, a probabilidade da próxima aterrissagem ter um desempenho ruim é maior. E se um piloto obteve um desempenho ruim em suas três últimas aterrissagens, a probabilidade da próxima aterrissagem ter um ótimo desempenho é maior. Este estudo provou o padrão previsto por Francis Galton (1822-1911), que dizia que tudo tende a regredir a sua média, como se existisse uma força propulsora empurrando para a média, restaurando a racionalidade. Foi este padrão de comportamento que baseou alguns dos ditados conhecidos hoje, como por exemplo: "tudo que sobe tem que descer", "o orgulho antecede a queda" e "o que os pais ganham os filhos dissipam". Os estudos de Galton deram uma grande contribuição aos estudos sobre administração de riscos e incertezas.

Kahneman e Tversky especularam sobre a possibilidade de existirem outras formas pelas quais as pessoas erram ao tentarem prever o futuro baseadas em informações do passado, do que somente ignorar a regressão à média. Mais tarde, eles desenvolveram a Teoria da Perspectiva, que, segundo Bernstein (1997), expõe padrões de comportamento nunca reconhecidos antes pelos estudiosos e teoriza sobre o processo decisório. A Teoria da Perspectiva aponta duas deficiências humanas que causam esses padrões. A primeira é o fato de a emoção muitas vezes destruir o autocontrole que é essencial à tomada racional de decisões. A segunda deficiência é o fato de as pessoas na maioria das vezes não entenderem de forma clara com que estão lidando. Criando em suas mentes o que os psicólogos chamam de frames ou molduras cognitivas.

O principal conceito que as Finanças Comportamentais abordam é o de "aversão às perdas". Este conceito diz que as pessoas não têm aversão ao risco e sim à perda. As pessoas preferem não sofrer a dor da perda do que o prazer de um ganho equivalente, ou seja, é preferível não perder $\mathrm{R} \$ 100,00$ a ganhar $\mathrm{R} \$ 100,00$. Também assumem riscos quando estão perdendo, mas são totalmente avessos ao risco quando estão ganhando. 
Contrariando conceitos econômicos que dizem que investidores devem arriscar quando estão ganhando e for avesso ao risco quando estão perdendo. Afinal de contas, "o primeiro prejuízo é sempre o melhor prejuízo".

Baseado no conceito de "aversão às perdas", pode-se observar também que o medo da perda faz com que pessoas tomem decisões de forma irracional, criando molduras cognitivas que as deixam cegas aos dados históricos e principalmente às probabilidades estatísticas. Como exemplo desta afirmação, pode-se citar aquelas pessoas que têm medo de viajar de avião, preferindo viajar de carro. Se for observada a estatística, constata-se que a viagem de avião é inúmeras vezes mais segura que uma viagem de carro, mas o simples fato de a pessoa imaginar que o avião poderá cair, causando um desastre, faz com que ela prefira viajar de carro. Outro exemplo seria o fato de investidores preferirem comprar ações que tem tido altas recentemente, na expectativa de que continuem em alta. Mas analisando do ponto de vista de que tudo tende a regredir à média, segundo Galton, a probabilidade de uma ação como esta continuar subindo é muito pequena. Em um último exemplo, podemos citar o fato de investidores, ao verem suas ações despencarem no mercado, hesitarem em vendê-las, esperando que em algum dia elas possam voltar a subir, correndo riscos maiores. Tudo isso para evitar a sensação de perder dinheiro, quando venderem suas ações por preços menores do que comprou.

Concentrando-se ainda no conceito de "aversão a perdas", pode-se observar que a irracionalidade em decisões e escolhas ocorre entre os indivíduos. Estes grupos de pessoas estudam teorias, conceitos, fórmulas e estatísticas, sempre procurando embasar suas decisões, mas, como todo ser humano, se deixam levar por emoções e conceitos errôneos em situações de incertezas e riscos.

Se as pessoas que estudam para tomar decisão acabam não tomando de forma racional, então se tem uma situação bastante contraditória. Estudar modelos, cálculos, estatísticas e teorias deveria fazer com que as percepções de valores e riscos fossem alteradas. Ao longo de um curso de graduação o aluno deveria adquirir capacidade de perceber probabilidades e compará-las perante situações de riscos. Deveria também expandir suas janelas cognitivas, percebendo um número maior de variáveis.

É importante ressaltar que, se observado sobre uma perspectiva holística, o curso tem como objetivo formar um profissional preparado para lidar com situações complexas e inter-relacionadas entre si, contendo incertezas e riscos de ganhos e perdas. Desta forma, torna-se interessante analisar se quanto mais um aluno estuda a ciência administrativa, mais preparado estará para tomar decisões em sua vida profissional.

Diante do exposto tem-se a seguinte questão de pesquisa: Um estudante de graduação muda a sua racionalidade no processo decisório ao longo de seus estudos?

Tomando como base a pesquisa realizada pelos psicólogos israelenses, Kahneman e Tversky (1997), este trabalho replica parte da pesquisa deles, utilizando estudantes de 
graduação. O objetivo é verificar a percepção de valor e comportamento perante riscos e incertezas dos mesmos. Analisando a evolução das percepções de valores do estudante, cumpre também abordar objetivos de pesquisas mais específicos, como por exemplo: comparar a pesquisa com os resultados obtidos por Kahneman e Tversky; verificar se os estudantes abordados tentam prever incertezas; se os estudantes consideram as probabilidades em situações de risco; e verificar se os estudantes preferem arriscar em situações de perdas e não arriscar em situações de ganho.

Como resultado de pesquisa, este trabalho visa compreender melhor como estudantes agem em situações de risco, delimitando suas percepções de valores e a consideração de probabilidades perante incertezas.

O trabalho expõe 6 partes, além desta introdução. O próximo capítulo trata de um breve referencial teórico. O capítulo três apresenta a metodologia utilizada. Após, analisamse as questões e os resultados obtidos. A parte cinco faz uma análise cruzada das respostas. O trabalho finaliza com a conclusão e recomendações.

\section{REFERENCIAL TEÓRICO}

As Finanças Comportamentais têm como principal objetivo identificar e compreender os frames, ilusões cognitivas que fazem com que pessoas cometam erros sistemáticos de avaliação de valores, probabilidades e riscos. As Finanças Comportamentais consideram que executivos, administradores, empresários e investidores nem sempre agem racionalmente, pois estão propensos aos efeitos das ilusões cognitivas.

No artigo de Kahneman e Tversky (1997), os autores discorreram sobre contextos cognitivos e psicológicos determinantes de escolhas com e sem riscos. Abordando o valor psicológico que induz a aversão ao risco quando existem ganhos e a busca por riscos quando existem perdas, Kahneman e Tversky aplicaram algumas pesquisas que provaram o fato de as pessoas preferirem não perder algo em detrimento de um ganho equivalente. Esta assimetria entre o modo das decisões envolvendo ganhos e o modo das decisões envolvendo perdas é intensamente demonstrada em seus estudos, sendo a conclusão mais útil da Teoria da Perspectiva. Uma das razões para explicar este fato poderia ser que as pessoas são mais sensíveis a estímulos negativos, como diz Tversky (Tversky apud BERNSTEIN, 1997, p. 274):

Provavelmente, a característica mais significativa e dominante da máquina de prazer humana é o fat.o de que as pessoas são muito mais sensíveis a estímulos negativos do que positivos... Pense sobre quão bem você se sente hoje e, depois, tente imaginar quão melhor você poderia se sentir... Existem algumas coisas que o fariam sentir-se melhor, mas o número de coisas que o fariam sentir-se pior é ilimitado. 
O processo de contabilidade mental também é abordado por Kahneman e Tversky (1997), explicando como as pessoas organizam as contas e transações em suas mentes, deixando transparecer anomalias psicológicas. $O$ modo como se percebem ganhos e perdas tem um grande poder de influência em decisões.

Simon (1957), um dos pioneiros nos estudos sobre processo decisório e também referência nesta área, escreveu sobre a psicologia nas decisões administrativas. Esse autor aborda a racionalidade na tomada de decisões, deixando claras as imperfeições do conhecimento que afetam o raciocínio humano. Segundo Simon (1957 p. 84),

a racionalidade requer um conhecimento completo e inalcançável das conseqüências exatas de cada escolha. Na verdade o ser humano possui apenas um conhecimento fragmentado das condições que cercam sua ação, e ligeira percepção das regularidades dos fenômenos e das leis que the permitiriam gerar futuras conseqüências com base no conhecimento das circunstâncias atuais.

Para Simon o ser humano age na maioria das vezes sob condições de racionalidade limitada, pois, como os humanos têm dificuldades de considerar e avaliar todas as informações e variáveis envolvidas em um processo de decisão, é feita escolha de apenas algumas variáveis para tomar a decisão necessária.

Simon (1960) deixa claro que o papel do gestor é tomar decisões. O exercício deste papel não se resume apenas ao ato final da escolha entre as alternativas disponíveis, mas todo o processo, o qual inclui: descobrir as ocasiões em que deve ser tomada a decisão, identificar os possíveis cursos de ação e decidir-se entre um deles. Simon (1960) ainda aborda instrumentos matemáticos que podem ser utilizados em decisões programadas, com o objetivo de tornar quantitativas situações em que não existem mensurações. Estes e vários outros modelos matemáticos são abordados nas escolas de negócios e em cursos como de contabilidade, administração ou economia, tanto de graduação como de pós-graduação. O que deixa evidente a importância da tomada de decisão racional no ambiente organizacional.

Segundo Bernstein (1997), as finanças modernas prevêem que as expectativas de investidores racionais serão equilibradas: um investidor racional superestimará uma parte do tempo e subestimará outra parte do tempo, mas não superestimará ou subestimará o tempo todo. Desta forma, os investidores racionais não estão entre as pessoas que sempre vêem o copo metade vazio ou metade cheia. Mas os investidores devem esperar perder ocasionalmente nos riscos que assumem, pois seria tolo não pensar nisto. Como a perda nos causa repulsa, tentamos sempre encontrar proteções contra surpresas desagradáveis, deixando de lado a análise de variáveis e principalmente a análise de probabilidades de uma perda realmente acontecer. 


\section{METODOLOGIA}

Conforme afirmado anteriormente, este trabalho teve como intuito replicar parte dos trabalhos de Daniel Kahneman e Amos Tversky (1997), mas diferentemente deles a população abordada foi alunos de graduação de uma universidade federal. Com isso foi possível analisar se os estudos nesta universidade mudam a racionalidade em decisões perante riscos e incerteza, como deveria acontecer segundo Simon (1960). Abordando a mesma metodologia de Kahneman e Tversky, também foi possível realizar análises comparativas deste trabalho com o trabalho desses autores, o que trouxe conclusões interessantes a respeito de Finanças Comportamentais.

A população escolhida foi dividida em três grupos. O primeiro grupo foi composto de alunos que estavam cursando o primeiro, segundo ou terceiro semestre, ou seja, alunos que estavam iniciando o curso. O segundo grupo foi composto de alunos que estavam cursando o quarto, quinto ou sexto semestre, ou seja, alunos que estavam no meio do curso. E finalmente o terceiro grupo foi composto por alunos que estavam cursando o sétimo, oitavo ou nono semestre, ou seja, alunos que estavam terminando seu curso. Com esta segmentação da amostra, foi possível confrontar as respostas dos três grupos, analisando a evolução na decisão racional em situações que envolvem riscos e incertezas.

É importante destacar que a amostra foi retirada de um curso de graduação que possui na sua estrutura curricular conteúdo de processo decisório. Em pelo menos duas disciplinas obrigatórias a abordagem da racionalidade econômica de Simon é assunto de programa. Além disso, também faz parte da estrutura curricular conhecimentos de estatística, mas especificamente de valor esperado. Isso significa dizer que parcela dos respondentes estaria apta a "acertarem" as perguntas formuladas.

O levantamento de dados primários foi feito por meio de aplicação de questionários nos três grupos da amostra. Os questionários continham a maioria das perguntas aplicadas nos trabalhos de Kahneman e Tversky, sendo divididos em questionários "Tipo A" e "Tipo B". O questionário "Tipo B" foi um espelho do questionário "Tipo A", ou seja, se no questionário "Tipo A" uma determinada pergunta enfatizou um ganho, no questionário "Tipo B" a mesma pergunta enfatizou uma perda. Desta forma foi possível comparar questões que envolvem perdas com questões que envolvem ganhos.

A quantidade de questionários aplicados em cada um dos grupos foi de 60 (sessenta) questionários, sendo 30 questionários "Tipo A" e 30 questionários "Tipo B". Isso totaliza 180 questionários. Os questionários foram construídos para que pudessem ser respondidos em poucos minutos pelos alunos, evitando assim problemas relacionados existentes em questionários longos. O total de questionários obtidos corresponde a uma amostra expressiva da população de alunos do curso dessa instituição de ensino, a saber, $17 \%$ do total de alunos. 
Os questionários foram aplicados em salas de aula, onde os alunos responderam voluntariamente, sem conhecer o objetivo nem o tema da pesquisa. A data de aplicação foi entre os dias 21 de setembro de 2005 a 17 de outubro de 2005.

As respostas dos questionários foram tabuladas e analisadas por meio do software SPSS (Statistical Package for the Social Sciences). Os questionários "Tipo A" foram tabulados separadamente dos questionários "Tipo B", pois tratam de questionários diferentes e desta forma possibilitou-se uma análise de "comparação de par". Nesta análise foram comparadas respostas de indivíduos de características iguais em relação ao objetivo da pesquisa (curso e semestre), mas que responderam a questionários espelhos.

Também foram analisadas as respostas dos indivíduos em relação a sua posição no fluxo do curso, o que permitiu verificar se, à medida que o aluno evolui em seus estudos, isto influencia suas decisões perante riscos e incertezas. A análise dos questionários também permitiu verificar se existem diferenças nas decisões entre os sexos desta população. Analisaram-se, assim, as respostas masculinas e respostas femininas em questões que envolvem perdas, ganhos, riscos e incertezas.

\section{ANÁLISE DOS RESULTADOS}

As questões foram analisadas verificando o valor matemático das alternativas e comparando os resultados com os resultados obtidos por Kahneman e Tverky (1997); desta forma foi possível diagnosticar como os respondentes se comportaram quanto à aversão a perdas e à falta de invariância².

Questão 1 ( $\mathbf{N}=180)$ Qual dos dois investimentos é o melhor para você?

A) $85 \%$ de chance de ganhar $\mathrm{R} \$ 1000,00$ e $15 \%$ de chance de nada ganhar (48\%)

B) Certeza de ganhar $\mathrm{R} \$ 800,00(52 \%)$

Nesta questão, o valor esperado da alternativa "A" é de $R \$ 850,00$ (85\% x $1000,00)$ e o valor esperado da alternativa "B" é de $R \$ 800,00(100 \%$ x 800,00). A escolha matematicamente correta ${ }^{3}$ seria a alternativa "A", com uma diferença de $R \$ 50,00$. Mas como se pode verificar, a resposta ficou muito próxima ao empate.

2 Os valores em percentuais após cada questão dizem respeito ao número de respondentes para cada alternativa.

$3 \quad$ Uma outra possível resposta poderia ser considerada a partir da teoria do matemático do século XVIII Daniel Bernoulli e de John Kelly. Esses autores consideram que a média geométrica é mais representativa para a determinação do valor esperado (POUNDSTONE, 2005, 190). Nesse caso, a resposta correta seria a alternativa "B". Entretanto como essa alternativa não é objeto de estudos por parte dos alunos de graduação, não foi considerada como "correta” para fins desse estudo. 
Diferentemente dos resultados encontrados nos trabalhos de Kahneman e Tversky (1997), em que a pesquisa demonstrou uma forte tendência à aversão ao risco quando um ganho é enfatizado, nesta amostra podemos constatar que não foi encontrado o mesmo padrão. No entanto deve-se ressaltar que cerca de metade da população respondeu de forma "incorreta".

\footnotetext{
Questão 2 - Questionário "Tipo A" (N = 90) Imagine que uma nova doença atingiu a população da cidade onde você reside. Um grupo de cientistas trabalha para conter a epidemia. Eles esperam que no mínimo 600 pessoas morram por causa da doença. Duas soluções para combater a doença foram encontradas: Solução "A" e Solução "B".

Se a Solução "A" for aplicada, 200 pessoas serão salvas. (48\%)

Se a Solução "B" for aplicada, há $1 / 3$ de probabilidade que 600 pessoas serão salvas e $2 / 3$ de probabilidade de ninguém ser salvo. (52\%)

Qual das duas soluções você escolheria?
}

Nesta questão, a solução "A" e a solução "B" são matematicamente iguais. Seja qual for a solução adotada, duzentas pessoas serão salvas e quatrocentas pessoas morrerão. (1/3 $x$ $600=200$ e $2 / 3 \times 600=400$ ). Mas a questão foi formulada enfatizando o ganho, ou seja, pessoas sendo salvas. Semelhantemente à questão 1 , os resultados também foram quase empates, não obtendo um padrão de preferência em relação ao risco, quando se enfatiza um ganho.

Este resultado diverge em muito do resultado divulgado por Kahneman e Tversky (1997), em que $72 \%$ escolheram a solução "A" e apenas $28 \%$ escolheram a solução "B", demonstrando uma clara aversão ao risco da amostra pesquisada pelos autores, quando se enfatiza um ganho. Entretanto, é importante destacar a diferença com o resultado obtido no Questionário “Tipo B”, conforme será feito a seguir.

\section{Questão 2 - Questionário "Tipo B" (N = 90)}

Imagine que uma nova doença atingiu a população da cidade onde você reside. Um grupo de cientistas trabalha para conter a epidemia. Eles esperam que no mínimo 600 pessoas morram por causa da doença. Duas soluções para combater a doença foram encontradas: Solução "A" e Solução "B".

Se a Solução "A" for aplicada, $\mathbf{4 0 0}$ pessoas morrerão. (32\%)

Se a Solução "B" for aplicada, há $1 / 3$ de probabilidade de que ninguém morrerá e $2 / 3$ de probabilidade de 600 pessoas morrerem. (68\%)

Qual das duas soluções você escolheria?

Nesta questão, a solução "A" e a solução "B" são matematicamente iguais. Seja qual for a solução adotada, quatrocentas pessoas morrerão e duzentas pessoas serão salvas 
$(1 / 3 \times 0=200$ e $2 / 3 \times 600=400)$. Mas a questão foi formulada enfatizando perda, ou seja, "pessoas morrerão". Comparando as respostas da questão 2 entre os questionários "Tipo A" e "Tipo B", pode-se constatar que os resultados demonstraram que os respondentes têm uma propensão ao risco quando percebem uma perda. Pois nos dois questionários, 400 pessoas morrerão, independentes da solução escolhida. Mas como se pode verificar, no questionário "Tipo B", onde foi enfatizada uma perda, $68 \%$ preferiram arriscar. Este resultado é semelhante ao resultado divulgado por Kahneman e Tversky (1997), em que apenas $22 \%$ escolheram a solução " $A$ " e $78 \%$ escolheram a solução "B", demonstrando uma clara propensão ao risco da amostra pesquisada pelos autores, quando se enfatiza uma perda.

Questão 3 ( $\mathbf{N}=\mathbf{1 8 0})$. Imagine que todos os seus colegas de sala deverão escolher um número de 0 a 100 . O objetivo é acertar o número que seria a metade da média de todos os números escolhidos.

Que número você escolheria?

Nesta questão o objetivo de todos foi acertar a metade da média de todos os números escolhidos. Esse é um problema que foi aplicado aos leitores do Financial Times por Thaler (2001) Isto exige que os respondentes tentem adivinhar qual seria o número que seu colega escolheria, pois a partir destes números ter-se-ia a metade da média. Ou seja, se todos responderem números aleatórios, a média tenderia para 50 , então a resposta correta seria em torno de 25 . Mas se todos pensarem desta forma e responder 25, a média das respostas tenderia para 25 , então a resposta correta seria em torno de 12,5. Se boa parte dos respondentes escolherem o número 12,5, então a média cairia para próximo ao número 15 , então a resposta correta estaria próxima ao número 7. Seguindo este raciocínio, a resposta mais racional seria o mais próximo possível de 0 (zero). Pois quanto mais o respondente raciocina na questão, mais sua resposta tende a 0 (zero). Analisando os resultados, cerca de $70 \%$ escolheram um número menor ou igual a 35 . Mas a moda foi 25 , com $40,55 \%$ dos casos. O que permite concluir que os respondentes empenharam raciocínio superficial ao responder a questão.

Questão 4 - Questionário "Tipo A" ( $\mathbf{N}=90)$. Escolha entre:

A) Certeza de ganhar $R \$ 240,00$ (46\%)

B) $25 \%$ de chance de ganhar $\mathrm{R} \$ 1000,00$ e $75 \%$ de chance de ganhar nada. $(54 \%)$

Nesta questão, a resposta matematicamente correta é a opção "B", pois seu valor esperado é de $\mathrm{R} \$ 250,00(25 \% \times 1000,00=250+75 \% \times 0,00=0)$. Diferentemente dos 
resultados obtidos por Kahneman e Tversky (1997), em que a opção "B" registrou apenas $16 \%$ (dezesseis por cento), nesta questão a maioria dos respondentes optou pela opção "B", deixando uma leve propensão ao risco quando se enfatiza o ganho. Mas não se pode desconsiderar o peso que se obteve na opção "A", quase a metade. Isto reflete certa ausência de polaridade quando a amostra pesquisada é colocada diante de situações de risco e há ganhos como ênfase.

Questão 4 - Questionário "Tipo B” ( $\mathbf{N}=90)$. Escolha entre:

A) Certeza de perder $\mathrm{R} \$ 750,00$. (21\%)

B) $75 \%$ de chance de perder $\mathrm{R} \$ 1000,00$ e $25 \%$ de chance de perder nada. $(79 \%)$

Nesta questão, as duas opções são matematicamente iguais $(75 \% \times 1000,00=$ $750,00+25 \% \times 0,00=0,00$ ), no entanto uma quantidade expressiva de respondentes preferiu a opção "B", demonstrando uma forte propensão ao risco quando deparados por uma situação em se enfatizam perdas. Pois na Questão 4 do Questionário "Tipo A", em que foi enfatizado um ganho, mesmo a opção "A" tendo um valor equivalente menor, quase metade dos respondentes preferiu escolhê-la. Este resultado foi muito semelhante ao encontrado por Kahneman e Tversky, em que $87 \%$ dos respondentes preferiram a opção "B" quando enfatizado uma perda.

Questão 5 - Questionário “Tipo A" ( $\mathbf{N}=90)$ Imagine que você decidiu ir ao teatro e comprou um ingresso por $\mathrm{R} \$ 30,00$. Quando chegou ao teatro, você descobre que perdeu o ingresso.

Você compraria outro ingresso?
A) $\operatorname{Sim}(54 \%)$
B) Não (46\%)

Nesta questão, a maioria preferiu comprar outro ingresso, demonstrando leve estimativa de valor para com o ingresso. Diferentemente dos resultados encontrados por Kahneman e Tversky (1997), em que a maioria preferiu não comprar outro ingresso (54\%), foi encontrada novamente uma falta de polaridade, haja vista que quase metade dos respondentes preferiu não comprar o ingresso.

Questão 5 - Questionário "Tipo B" $(\mathbf{N}=\mathbf{9 0})$. Imagine que você decidiu ir a um teatro no qual o ingresso custa $R \$ 30,00$. Quando chegou ao teatro, você descobre que perdeu $\mathrm{R} \$ 30,00$.

Você ainda gastaria $\mathrm{R} \$ 30,00$ para comprar outro ingresso?
A) $\operatorname{Sim}(73 \%)$
B) Não $(27 \%)$ 
Nesta questão, diferentemente dos resultados encontrados na Questão 5 do Questionário "Tipo A", a maioria preferiu comprar outro ingresso, demonstrando pouca estimativa de valor para com o dinheiro. Os resultados encontrados por Kahneman e Tversky foram muito semelhantes ao da amostra aqui pesquisada, demonstrando que os respondentes realmente percebem pouco valor na quantia necessária para comprar o ingresso.

Fazendo uma análise comparativa entre questões, verificou-se que na questão 2 dos questionários "Tipo A", em que houve ênfase no ganhos (pessoas serão salvas), os resultados ficaram bem distribuídos. E na questão 2 dos questionários "Tipo B", houve ênfase nas perdas (pessoas morrerão), e os resultados mostraram que a maioria absoluta preferiu arriscar. Estes resultados mostram que não houve uma falta de invariância dos respondentes, pois quando enfatizado ganhos em situações de risco, quase metade dos respondentes preferiram arriscar e, quando enfatizado perdas, uma quantidade maior de respondentes também preferiu arriscar.

Comparando a questão 4 entre os dois questionários, percebe-se também que, quando enfatizado um ganho (questionário "Tipo A"), a maioria absoluta dos respondentes preferiu arriscar. E, quando enfatizado uma perda (questionário "Tipo B”), a maioria também preferiu arriscar. Mais uma vez não foi encontrado uma falta de invariância dos respondentes.

Nestes dois últimos casos citados, percebe-se apenas que, quando enfatizada uma perda, o número de respondentes que preferem arriscar, é no mínimo duas vezes maior que o número de respondentes que preferem não arriscar. Isto mostra que os respondentes, mesmo não apresentando falta de invariância, estão suscetíveis à aversão à perda.

\section{ANÁLISE DOS CRUZAMENTOS}

Com o intuito de analisar se o grau de aprendizado possui relação com a percepção de valor e a propensão ao risco do aluno, foram realizados cruzamentos comparando-se o semestre com as respostas dos questionários.

Na primeira questão abordada nos questionários, onde é colocada uma situação de risco enfatizando-se um ganho, não foi encontrado nenhum padrão de respostas que pudesse estar relacionada com a posição no fluxo do aluno no curso.

Nos questionários "Tipo A", onde foram enfatizados ganhos, como nas questões 2 e 4 , as respostas também não obedeceram a nenhum padrão quanto ao semestre. Mas na questão 5, onde foi colocada uma situação em que se perde um ingresso para o teatro, e quando perguntado se o aluno compraria outro ingresso, os resultados dos três grupos de semestres tiveram respostas semelhantes entre si e muito semelhantes ao do resultado obtido por Kahneman e Tversky (1997) (Tabela 1). 


\begin{tabular}{l|l|l|l|l}
\hline \multirow{2}{*}{ Semestre } & \multicolumn{2}{|l|}{ Questão 5 Tipo A } & \multicolumn{2}{l}{ Questão 5 Tipo B } \\
\cline { 2 - 5 } & Sim & Não & Sim & Não \\
\hline
\end{tabular}

$\begin{array}{lll}\text { Do } 1 .^{\circ} \text { ao } 3 .^{\circ} & 56,70 \% 43,30 \% & 53,30 \% 46,70 \% \\ \text { Do } 4 .^{\circ} \text { ao } 6 .^{\circ} & 53,30 \% 46,70 \% & 80,00 \% 20,00 \% \\ \text { Do } 7 .^{\circ} \text { ao } 9 .^{\circ} & 53,30 \% 46,70 \% & 86,70 \% 13,30 \% \\ \text { Total } & 54,40 \% 45,60 \% & 73,30 \% 26,70 \%\end{array}$

\section{Tabela 1 - Relação entre a Questão 5 Tipo A e o semestre Fonte: Elaboração Própria}

Nos questionários "Tipo B", nas questões 2 e 4, foram colocadas situações de risco enfatizando-se perdas. Nestas questões também não foram encontrados padrões de respostas relacionados aos grupos de semestre. Apenas na questão 5 (cinco), onde foi colocada uma situação em que se perde $\mathrm{R} \$ 30,00$ ao ir para o teatro e pergunta-se se o aluno ainda gastaria $\mathrm{R} \$ 30,00$ para comprar outro ingresso, existiu um alto grau de correlação entre as respostas e a posição no fluxo do aluno no curso. Nesta questão, à medida que os respondentes avançam no curso, tendem a responder a opção "A", ou seja, sim, ainda gastariam $\mathrm{R} \$ 30,00$ para comprar o ingresso (segunda parte da Tabela 1).

Com o intuito de analisar se o sexo do respondente possui relação com a percepção de valor e a propensão ao risco, foram realizados cruzamentos comparando-se o sexo com as respostas dos questionários. Entre os cruzamentos realizados, foi encontrada correlação apenas na primeira questão abordada no questionário "Tipo B", onde é colocada uma situação de risco enfatizando-se um ganho. Os respondentes do sexo feminino escolheram em sua grande maioria a opção "B", deixando claro uma aversão ao risco quando enfatizado um ganho (Tabela 2).

Sexo A B Tabela 2 - Relação entre o sexo e aversão ao risco Fonte: Elaboração Própria

\begin{tabular}{lll}
\hline Masculino & $65,40 \%$ & $34,60 \%$ \\
Feminino & $28,90 \%$ & $71,10 \%$ \\
Total & $50,00 \%$ & $50,00 \%$ \\
\hline
\end{tabular}

\section{CONCLUSÕES E RECOMENDAÇÕES}

O principal conceito que Finanças Comportamentais aborda é o de "aversão a perdas". Este conceito diz que as pessoas não têm aversão ao risco e sim à perda. Baseado no conceito de aversão a perdas, pode-se observar também que o medo da perda faz com que pessoas tomem decisões de forma irracional, criando molduras cognitivas que as deixam cegas aos dados históricos e principalmente às probabilidades estatísticas. 
Ao longo de um curso de graduação voltado para negócios, o aluno deveria adquirir capacidade de perceber probabilidades e compará-las perante situações de riscos. Pois estudar modelos, cálculos, estatísticas e teorias, deveria fazer com que as percepções de valores e riscos fossem alteradas.

Entre as questões analisadas da pesquisa, quando se enfatizou um ganho diante de uma situação de risco, os respondentes comportaram-se sem definir uma polaridade, não apresentando uma aversão ao risco, tampouco uma propensão. Tais constatações divergem dos estudos de Kahneman e Tversky (1997), nos quais se apresentam uma forte aversão ao risco nestas mesmas ocasiões.

Porém, quando foi enfatizada perda em questões de risco para com a amostra estudada, os resultados foram muito semelhantes aos encontrados por Kahneman e Tversky (1997), revelando uma forte propensão ao risco em situações de perdas.

Comparando os estudantes pesquisados com uma população qualquer estudada por Kahneman e Tversky, verificou-se que existe uma divergência apenas em situações em que um ganho é percebido. Estes resultados mostram que não existe uma falta de invariância entre os pesquisados quando se enfatiza um ganho. O que leva esta pesquisa a ir de encontro com a seguinte afirmação dos autores Kahneman e Tversky (Kahneman e Tversky 1984. Apud BERNSTEIN, Peter L. Desafio aos deuses, p. 275):

A falta de invariância é generalizada e firme. Ela é comum entre respondentes sofisticados, bem como entre ingênuos [...] (grifo nosso). Os respondentes, confrontados com suas respostas conflitantes, costumam ficar intrigados. Mesmo depois de reler os problemas, eles continuam avessos ao risco na versão das "vidas salvas", embora procurem o risco na versão das "vidas perdidas"; e eles também querem obedecer à invariância e dar respostas coerentes a ambas as versões [...] A moral desses resultados é perturbadora. A invariância é normativamente essencial (o que deveríamos fazer), intuitivamente irresistível e psicologicamente inviável.

Entre as questões analisadas, quando se enfatizou uma perda diante de uma situação de risco, os respondentes comportaram-se semelhantemente aos estudos de Kahneman e Tversky (1997), apontando uma forte propensão ao risco, confirmando a afirmação de Tversky (1990 p. 75; apud BERNSTEIN, Peter L. Desafio aos deuses. p. 273) de que "a principal força propulsora é a aversão à perda [...] Não se trata tanto de que as pessoas odeiam a incerteza - mas, pelo contrário, de que odeiam perder".

Nas questões 5 dos questionários "Tipo A" e "Tipo B", foram abordadas questões que procuram verificar a "contabilidade mental" dos respondentes. Nos questionários "Tipo A", os respondentes deparavam com a situação em que iam ao teatro e no caminho perdiam o ingresso, tendo que decidir se comprariam ou não outro ingresso. Já na questão 5 dos questionários “Tipo B", a situação colocada foi que os respondentes perdiam os $\mathrm{R} \$ 30,00$ 
que gastariam para comprar o ingresso. Nas duas situações colocadas, quer tenha perdido o ingresso, quer tenha perdido os $\mathrm{R} \$ 30,00$, se você decidisse ir ao teatro, teria que se privar de $R \$ 60,00$ e, se decidisse não ir ao teatro, teria que privar-se de $R \$ 30,00$. $\mathrm{Na}$ pesquisa feita por Kahneman e Tversky (1997), a maioria dos respondentes preferiu não comprar outro ingresso, mas quando perguntado se ainda estariam dispostos a comprar o ingresso, depois da perda do dinheiro para o mesmo, a maioria dos respondentes disseram que sim, ainda gastariam dinheiro para comprar o ingresso. Segundo Bernstein (1996), este fato levou os autores a verificar uma falta de invariância entre os pesquisados. Era como se no primeiro caso, quando se perde o ingresso, a conta do teatro seria duas vezes maior se o respondente comprasse outro ingresso. Mas no segundo caso, quando se perde o dinheiro para comprar o ingresso, a conta do teatro continuaria a mesma se o respondente ainda comprasse o ingresso. E o dinheiro gasto a mais, sairia de outras contas no futuro distante, como, por exemplo, um almoço ou uma programação de lazer futura.

Mas nos resultados encontrados nesta pesquisa, encontra se uma divergência em relação à pesquisa de Kahneman e Tversky (1997). Nas duas situações abordadas os respondentes disseram "sim", comprariam outro ingresso. E "sim", ainda gastariam R \$30,00 para comprar o ingresso. Não demonstrando, desta forma, a falta de invariância encontrada por Kahneman e Tversky.

Verificando os resultados da pesquisa em relação ao sexo dos respondentes, foi encontrada uma forte "Correlação de Pearson" significativa $(0,360)$ na questão 1 (um) do questionário "Tipo B", onde os respondentes do sexo feminino foram extremamente avessos ao risco, mesmo quando a outra opção mostrava um maior valor esperado, enquanto os respondentes do sexo masculino foram extremamente propensos ao risco. Nas outras questões, quando se analisa o resultado em relação ao sexo, tem-se uma leve aversão ao risco dos respondentes do sexo feminino. O que leva a concluir que os respondentes do sexo feminino aqui pesquisados possuem uma aversão a perdas um pouco mais aguçada que os do sexo masculino.

Analisando os resultados da pesquisa em relação ao semestre cursado pelos respondentes, pôde-se verificar que não existe correlação suficiente para afirmar que os estudos interferem no raciocínio do indivíduo em situações de risco. Não foi encontrada, entre as questões da pesquisa, uma falta de invariância ou um padrão de respostas entre os grupos de semestres analisados. O que leva a concluir que os estudantes pesquisados não mudam sua racionalidade no processo decisório ao longo de seus estudos. Esta conclusão se faz perceber algo intrigante dentro da ciência administrativa. Os estudantes aqui pesquisados estudam metodologias desenvolvidas por Simon entre outros autores de processo decisório, aprendem a usar ferramentas como árvore de decisão, estudam análise de investimentos, entre outros. Mas todos estes estudos não interferem em seu raciocínio quando se vê diante de uma situação de risco. 
Os resultados aqui concluídos com esta pesquisa demonstram quão vasto e promissor é o estudo em Finanças Comportamentais. Os autores Daniel Kahneman e Amós Tversky deram uma grande contribuição nesta área, mas, como podemos ver, seus estudos foram apenas um elemento deflagrador para grandes descobertas envolvendo a psicologia, finanças e risco.

\section{REFERÊNCIAS}

BERNSTEIN, Peter L. Desafio aos Deuses: A Fascinante História do Risco. Editora Campus: Rio de Janeiro, 1997.

KAHNEMAN, Daniel e TVERSKY, Amos. Choices, Values, and Frames. Princeton University Press, 1997.

MODIGLIANI F.; MILLER Merton H. Dividend Policy, Growth and the Valuation of Shares, Journal of Business, 34:411-433, Outubro de 1961.

NEUMANN, J. VON. e MORGENSTERN, O. Theory of Games and Economic Behavior. Princeton University Press, 1944.

POUNDSTONE, W. Fortune's formula. New York: Hill and Wang, 2005.

SHARPE, W. F. Capital asset prices: A theory of market equilibrium under conditions of risk. Journal of Finance, setembro, p. 425-443, 1964.

SHLEIFER, Andrei. Inefficient Markets. Oxford: Oxford University, 2000. SIMON, Herbert Alexander. Comportamento Administrativo. Fundação Getúlio Vargas: Rio de Janeiro, 1957.

SIMON, Herbert Alexander. A capacidade de decisão e de liderança. Editora Fundo de Cultura: Rio de Janeiro, 1960.

THALER, Richard. Dando aos mercados uma dimensão humana. Dominando Finanças. São Paulo: Makron, 2001.

VIANA, Ricardo J. A. L. O efeito da miopia e a aversão à perda nas decisões de risco. Dissertação (Mestrado em Economia) - Departamento de Economia, Universidade de Brasília, Brasília, 2005. 